\title{
An Immunoblotting Procedure Following Agarose Gel Electrophoresis for Detection of Bence Jones Proteinuria Compared with Immunofixation and Quantitative Light Chain Determination
}

\author{
By Wolfgang Withold and Hans Reinauer \\ Institut für Klinische Chemie und Laboratoriumsdiagnostik, Medizinische Einrichtungen der \\ Heinrich-Heine-Universität Düsseldorf, Germany
}

(Received November 14, 1994/January 2, 1995)

Dedicated to the memory of Professor Dr. Ahmad Fateh-Moghadam

Summary: An immunoblotting procedure for the sensitive detection of Bence Jones proteinuria following agarose gel electrophoresis was developed.

After immunonephelometric determination of urinary $\kappa$ and $\lambda$ light chains [employing antisera to human $\kappa$ and $\lambda$ light chains (free + bound)], urine samples (diluted to $2.5 \mathrm{mg} / \mathrm{l} \kappa$ and $\lambda$ light chains, respectively) were electrophoretically separated using the Paragon ${ }^{\circledR}$ system and blotted by capillary diffusion onto nitrocellulose. Rabbit antihuman $\kappa$ and $\lambda$ light chains reacted to $\kappa$ and $\lambda$ light chains attached to the membrane. Goat anti-rabbit IgG alkaline phosphatase conjugate was employed as detection system.

The detection limit of the immunoblotting procedure (monoclonal component, as determined by serial dilutions) was $0.3 \mathrm{mg} / \mathrm{l}$ urine. Among 65 urine specimens received for routine testing for Bence Jones proteinuria, 32 monoclonal components (in 20 urine samples) were found by immunoblotting compared with 10 monoclonal components (in 9 urine samples) detected by immunofixation. In only 5 out of these 65 urine samples a $\mathrm{k} / \lambda$ ratio (as determined immunonephelometrically) $<1$ or $>5.2$ (decision limits for discriminating between monoclonal and polyclonal urinary light chains; Boege F, Koehler B, Liebermann F. Eur J Clin Chem Clin Biochem 1990; 28:37-42) was observed.

In conclusion, the immunoblotting method is superior to both immunofixation and immunonephelometry with respect to the diagnostic sensitivity for detection of Bence Jones proteinuria.

\section{Introduction}

The detection of monoclonal free light chains (Bence Jones proteins) in urine samples provides important diagnostic and prognostic information of B-cell malignancies with a monoclonal proliferation of plasma and lymphoplasmacytoid cells, respectively.

The usual approach for qualitative detection of Bence Jones proteins in urine samples by immunofixation following agarose gel electrophoresis is more sensitive than immunoelectrophoresis (for review see 1.c. (1)).
Another method (yielding quantitative results) is the immunochemical determination of $\kappa$ and $\lambda$ light chain concentrations in urine samples (2).

Immunoblotting has been proposed as an alternative method for qualitative detection as well as heavy and light chain typing of human paraproteins (3). By this method the protein pattern generated in a gel is transferred to a porous membrane (e.g. nitrocellulose) to produce a replica; the purpose of this transfer is to facilitate the binding of antibodies to their corresponding antigens 
on the membrane yielding a higher analytical sensitivity compared with immunofixation (for review see l.c. (4)).

The present communication describes an immunoblotting procedure (following agarose gel electrophoresis) for detection of Bence Jones proteinuria in comparison with immunofixation (following agarose gel electrophoresis) and immunonephelometric determination of light chain concentrations.

\section{Materials and Methods}

\section{Samples}

We examined aliquots from 24-h collections of 65 urine samples. These were all urine samples sent to our laboratory for routine screening for Bence Jones proteinuria over a 2-month period.

Immunoblotting following agarose gel electrophoresis

Urine samples were diluted to $2.5 \mathrm{mg} / \mathrm{l} \kappa$ and $\lambda$ light chains, respectively (as determined immunonephelometrically; see below) with 'B-2 barbital buffer' (component of the Paragon ${ }^{\circledR}$ electrophoresis kit; see below). In case of urine samples showing light chain concentrations below the detection limit (as determined immunonephelometrically; see below) native urines were employed. Five $\mu l$ of diluted urine samples were electrophoretically separated in agarose gels for 30 min using the Paragon ${ }^{\circledR}$ system according to the manufacturer's recommendations.

Immunoblotting was performed by capillary diffusion as described earlier (3) employing

(a) an Immun-Blot ${ }^{\circledR}$ Assay Kit (Bio-Rad Laboratories GmbH, Munich, Germany; no. 170-6460), (b) nitrocellulose strips as blotting membranes (Bio-Rad Laboratories $\mathrm{GmbH}$; no. 162-0114) and

(c) rabbit antisera (DAKO GmbH, Hamburg, Germany) against human $\kappa$ and $\lambda$ light chains (bound + free) (no. A 191 and A 193). The occurrence of at least one homogeneous band reacting with only one of these two antisera was considered to represent the presence of a monoclonal immunoglobulin. In order to differentiate between Bence Jones proteins and an urinary excretion of intact monoclonal immunoglobulins, antisera against $\kappa$ free light chains and $\lambda$ free light chains (no. A 100 and A 101) as well as antisera against $\gamma, \alpha$ and $\mu$ chains (no. A 423, A 262 and A 425) were used. All antisera were diluted $1+100$ with Tris $\cdot \mathrm{HCl}$ buffer $(20$ $\mathrm{mmol} / \mathrm{l}$, pH 7.5 , with $500 \mathrm{mmol} / \mathrm{l} \mathrm{NaCl}$ ) containing $0.5 \mathrm{ml} / 1$ Tween ${ }^{\circledR} 20$ and $10 \mathrm{~g} / \mathrm{l}$ gelatine. Goat anti-rabbit IgG alkaline phosphatase conjugate was employed as second antibody. Colour development took place with nitroblue tetrazolium and an indolyl phosphate derivative.

Immunofixation following agarose gel electrophoresis Immunofixation was performed employing the Paragon ${ }^{\circledR}$ Immunofixation electrophoresis kit (Beckman Instruments $\mathrm{GmbH}$; no. 444930) according to the manufacturer's recommendations. The urine samples were concentrated up to a total protein concentration of $10 \mathrm{~g} / \mathrm{l}$ with Amicon 'B15' concentrators. For a definition of monoclonality of the urinary immunoglobulins see under 'immunoblotting following agarose gel electrophoresis'.

\section{Quantitative determination of light chains} in urine samples

Quantitative light chain determinations in urine samples were performed with the help of a Behring Nephelometer Analyzer (Behringwerke AG, Marburg) employing ' $\mathrm{N}$ protein standard serum' (lot no. 067650) and 'NA antisera' to human immunoglobulins/Lchains ( $\kappa$ and $\lambda$ ) (lot. no. 101439 and no. 101453). The assay protocol was according to the manufacturer's recommendations. The de-
1

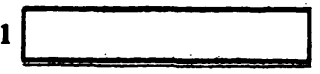

2

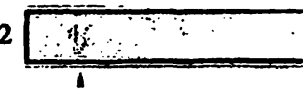

3

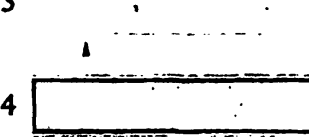

5
1

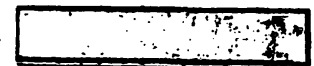

$2 \longdiv { . 7 }$

3

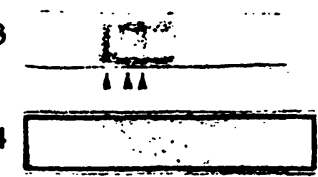

5

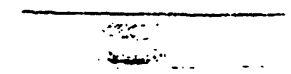

b

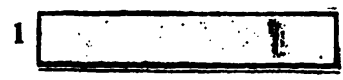

2

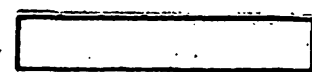

3

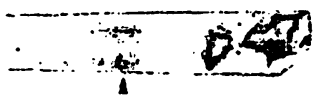

4

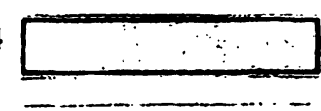

Fig. 1 Comparison between immunoblotting and immunofixation for detection of monoclonal immunoglobulins in urine samples. The cathode is on the left, the anode on the right.

Lane 1: Urine protein electrophoresis (employing 'blue stain' [component of the Paragon ${ }^{\circledR}$ electrophoresis kit])

Lane 2: Immunofixation (employing antisera against $\kappa$ light chains [bound + free])

Lane 3: Immunoblotting (employing antisera against $\kappa$ light chains [bound + free])

Lane 4: Immunofixation (employing antisera against $\lambda$ light chains [bound + free])

Lane 5: Immunoblotting (employing antisera against $\lambda$ light chains [bound + free])
Fig. 1a Detection of an intact IgGK paraprotein by both methods (heavy chain typing not shown).

Fig. 1b Polyclonal $\kappa$ pattern by immunofixation but monoclonal pattern by immunoblotting.

Fig. 1c A monoclonal band (Bence Jones $\kappa$ ) detected only by immunoblotting whereas immunofixation shows neither a polyclonal nor a monoclonal pattern.

The monoclonal $\kappa$ bands detected by immunoblotting (as shown in figs. $\mathrm{lb}$ and $\mathrm{lc}$ ) were proved to be Bence Jones proteins by separately employing antisera against heavy and free light chains. 
tection limit was $3 \mathrm{mg} / \mathrm{l}$ for $\lambda$ chains and $5 \mathrm{mg} / \mathrm{l}$ for $\kappa$ chains. An optimal discrimination between monoclonal and polyclonal urinary light chains was assumed to be given using decision limit values of the $\kappa / \lambda$ ratio of 5.2 and 1.0 , respectively (2).

\section{Results}

Immunoblotting - detection limit and frequency of monoclonal bands observed

Serial dilutions with several urine samples containing monoclonal free $\kappa$ and free $\lambda$ light chains were done. The detection limit (monoclonal component concentration) was $0.3 \mathrm{mg} / \mathrm{l}$ urine.

In 65 urine samples, a total of 32 monoclonal components was found in 20 urines by immunoblotting ( 24 free $\kappa$ light chains, 4 free $\lambda$ light chains, 2 monoclonal $\operatorname{IgGK}$ and 2 monoclonal $\operatorname{IgG} \lambda$ ). The number of monoclonal bands observed by immunoblotting ranged from 1 to 4 per urine sample (figs. 1a to $1 \mathrm{c}$ ).

\section{Comparison between immunoblotting and immunofixation}

Out of 65 urine samples, a total of 10 monoclonal components was found in 9 urines by immunofixation ( 8 free $\kappa$ light chains, 1 free $\lambda$ light chain and 1 monoclonal IgGK). The number of monoclonal bands observed by immunofixation ranged from 1 to 2 per urine sample. For comparison between immunofixation and immunoblotting see table 1 .

\section{Comparison between immunoblotting and quantitative light chain determination}

Range of $\kappa$ light chain concentrations was $<5$ to 160 $\mathrm{mg} / \mathrm{l}$ (median $\pm \mathrm{SEM}: 21 \pm 4 \mathrm{mg} / \mathrm{l}$ ) whereas the range of $\lambda$ light chain concentrations was $<3$ to $117 \mathrm{mg} / \mathrm{l}$ (median \pm SEM: $13 \pm 3 \mathrm{mg} / \mathrm{l}$ ). In 5 out of 65 urine samples a $k / \lambda$ ratio $<1$ or $>5.2$ (decision limits for discriminating between monoclonal and polyclonal urinary light chains as suggested by 1.c. (2)) was observed.
For comparison between quantitative values and immunoblotting see table 2 .

\section{Discussion}

Immunoblotting is superior to immunofixation as well as immunonephelometric determination of light chains with respect to the detection of Bence Jones proteinuria. This applies not only to the number of urine samples being positive for monoclonal components but also to the number of monoclonal bands detected per urine sample. Multiple bands appearing in urine samples are most probably due to the association of monomeric light chains to multimers (5) or due to a proteolytic degradation of the Bence Jones proteins yielding charge as well as size isoforms (6).

The increased diagnostic sensitivity of the immunoblotting method $(7,8)$ as compared with immunofixation is due to several factors:

(a) No concentration step is required thus avoiding loss of Bence Jones proteins during ultrafiltration.

(b) Immunoblotting is characterized by higher analytical sensitivity because the transfer of the proteins to the blotting membrane facilitates diffusion of the antibodies to their corresponding antigens (4). The typical detection limit of an immunofixation procedure is only $20-30$ $\mathrm{mg} / \mathrm{l}(9)$ compared with $0.3 \mathrm{mg} / \mathrm{l}$ as found for our immunoblotting method.

(c) Repeated analyses of different antigen concentrations have to be performed for immunofixation procedures because a precipitation of immune complexes is required.

By application of immunoblotting, however, monoclonal bands can be seen using only one combination of sample concentration and antibody dilution.

For the quantitative determination of urinary immunoglobulin light chains the following has to be taken into account:

Tab. 1 Comparison between immunoblotting and immunofixation.

\begin{tabular}{|c|c|c|c|}
\hline & \multicolumn{3}{|l|}{ Number of urine samples } \\
\hline & $\begin{array}{l}\text { with } \\
\text { monoclonal bands } \\
\text { found by immunofixation }\end{array}$ & $\begin{array}{l}\text { without } \\
\text { monoclonal bands } \\
\text { found by immunofixation }\end{array}$ & $\Sigma$ \\
\hline \multirow[t]{2}{*}{$\begin{array}{l}\text { with monoclonal bands found by immunoblotting } \\
\text { without monoclonal bands found by immunoblotting }\end{array}$} & $\begin{array}{l}9(14 \%) \\
0(0 \%)\end{array}$ & $\begin{array}{l}11(17 \%) \\
45(69 \%)\end{array}$ & $\begin{array}{ll}20 & (31 \%) \\
45 & (69 \%)\end{array}$ \\
\hline & $9(14 \%)$ & $56(86 \%)$ & $65(100 \%)$ \\
\hline
\end{tabular}


Tab. 2 Comparison between immumoblotting and quantitative light chain concentrations.

\begin{tabular}{|c|c|c|c|}
\hline & \multicolumn{3}{|c|}{ Number of urine samples } \\
\hline & $\begin{array}{l}\text { with a } \kappa / \lambda \text { ratio } \\
<1 \text { or }>5.2\end{array}$ & $\begin{array}{l}\text { with a } \kappa / \lambda \text { ratio } \\
>1 \text { and }<5.2\end{array}$ & $\Sigma$ \\
\hline $\begin{array}{l}\text { with monoclonal bands found by immunoblotting } \\
\text { without monoclonal bands found by immunoblotting }\end{array}$ & $\begin{array}{l}4(6 \%) \\
1 *(1 \%)\end{array}$ & $\begin{array}{l}16(25 \%) \\
44(68 \%)\end{array}$ & $\begin{array}{ll}20 & (31 \%) \\
45 & (69 \%)\end{array}$ \\
\hline & $5(7 \%)$ & $60(93 \%)$ & $65(100 \%)$ \\
\hline
\end{tabular}

* Re-analysis of this sample $(\lambda$ concentration $=40 \mathrm{mg} / \mathrm{l} ; \kappa / \lambda$ ratio $=0.25$ ) by immunoblotting and immunofixation confirmed a poly- clonal pattern of free $\kappa$ and $\lambda$ light chains.

ples examined by them with monoclonal bands (as detected by immunofixation) were characterized by altered $\kappa / \lambda$ ratios. A possible explanation for this discrepancy are the higher concentrations of the immunoglobulin light chains in the urine samples examined by Boege et al. (2) $(13-30000 \mathrm{mg} / \mathrm{l})$. Moreover, the tendency of free light chains in urine samples to form reversible polymers may cause inaccuracies of the immunonephelometric determination (2).

The high sensitivity of the immunoblotting method presented in this communication may be used $e . g$. for the detection of residual tumour mass in patients with $B$ cell malignancies following chemotherapy.

\section{Acknowledgement}

The technical help of cand. med. M. Aivado for performing the immunoblotting procedure is gratefully acknowledged. We thank the technical assistants of the department of immunology for collection of urine samples.

\section{References}

1. The Association of Clinical Pathologists. Laboratory investigation of paraproteinaemia. J Clin Pathol 1988; 41:776-85.

2. Boege $F$, Koehler $B$, Liebermann F. Identification and quantification of Bence-Jones proteinuria by automated nephelometric screening. Eur J Clin Chem Clin Biochem 1990; 28:37-42.

3. Withold W, Rick W. An immunoblotting procedure following agarose gel electrophoresis for subclass typing of IgG paraproteins in human sera. Eur J Clin Chem Clin Biochem 1993; $31: 17-21$.

4. Towbin H, Staehelin T, Gordon J. Immunoblotting in the clinical laboratory. J Clin Chem Clin Biochem 1989; 27:495-501.

5. Dear Dr. [Bence] Jones [editorial]. Clin Chem 1991; 37:1557-8.

6. Norden AGW, Fulcher LM, Flynn FV. Immunoglobulin lightchain immunoblots of urine proteins from patients with tubular and Bence-Jones proteinuria. Clin Chim Acta 1987; 166:307-15.

7. Graziani MS, Righetti G. Immunoblotting for detecting Bence Jones proteinuria [letter]. Clin Chem 1987; 33:1079-80.

8. Heys A, Norden AGW, Fulcher LM, Flynn FV. Bence Jones protein detection: a rapid immunoblotting technique for rou-

tine use on unconcentrated urine. Ann Clin Biochem 1986; 23:571-6.

9. Fateh-Moghadam A, Thomas L. Monoklonale Immunglobuline. In: Thomas L, editor. Labor and Diagnose. Marburg: Medizinische Verlagsgesellschaft, 1992:880-907.

10. Boege F, Koehler B, Schwab M. Die diagnostische Wertigkeit des Kappa/Lambda-Leichtketten-Quotienten bei Nachweis, Identifizierung und Quantifizierung monoklonaler Immunglobuline im Vergleich zu Immunfixation, M-Gradient und quantitativer Immunglobulinbestimmung. Untersuchungen an 101 Patientenseren. Lab. Med. 1989; 13:369-74.

Dr. med. Wolfgang Withold Institut für Klinische Chemie und Laboratoriumsdiagnostik Medizinische Einrichtungen der Heinrich-Heine-Universität Düsseldorf Moorenstraße 5 D-40225 Düsseldorf Germany 